\title{
Changing Trends in the Treatment of Mandibular Fracture
}

\author{
Mohammad Waheed El-Anwar ${ }^{1}$ \\ 1 Deparment of Otorhinolaryngology Head and Neck Surgery, \\ Faculty of Medicine, Zagazig University, Zagazig, Egypt \\ Int Arch Otorhinolaryngol 2018;22:195-196.
}

Address for correspondence Mohammad Waheed El-Anwar, MD, Deparment of Otorhinolaryngology Head and Neck Surgery, Faculty of Medicine, Zagazig University, Zagazig 0020552309843, Egypt (e-mail: mwenteg@yahoo.com; mwenteg1973@gmail.com).

Immediate postoperative release of the rigid MMF after OR/IF using titanium miniplate(s) was confirmed to be as effective and safe as maintaining postoperative rigid MMF for different durations. ${ }^{5,6}$ However, the use of rigid intraoperative MMF increases the operative time, cost, blood-transmitted diseases to patients and/or the surgical team and the risk of tooth injury. These factors opened the door for recent studies searching for simpler, faster, easier and at the same time effective OR/IF of the fractured mandible. ${ }^{4}$

After a prospective comparative study, El-Anwar et $\mathrm{al}^{4}$ found that manual MMF (3MF) during the OR/IF of selected cases of mandibular fractures could be successfully performed, allowing for a more rapid and less complex procedure limited to the mandible. In addition to the gained benefits of immediate postoperative mandible mobilization, 3MF provided significantly shorter operative times $(p<0001)$, less risk of blood-transmitted diseases to the surgical team and the patient, and significantly better early mouth opening ( $p=0.0015$ ).

In a later study of the the advantages of the rapid $3 \mathrm{MF}$ procedure that is limited to the mandible, El-Anwar and Hegab $^{9}$ were the first to investigate the $3 \mathrm{MF}$ repair of fractured mandibles under regional anesthesia comparing the results with a control group in which $3 \mathrm{MF}$ was performed under general anesthesia (GA). They used an extraoral mandibular nerve block, and concluded that regional anesthesia can replace GA in the OR/IF of selected cases of mandibular fracture (parasymphyseal fracture) without reported complications, providing an optimal solution when GA is not recommended or contraindicated.

More studies applying regional anesthesia in other types of mandibular fracture are expected to be conducted in the near future. The maxillofacial surgeons' awareness of those easier and reliable alternatives needs to be increased so these simpler and effective repairs become more popular.

When there is a need to maintain a postoperative rigid MMF, various methods have been employed over time. Even

Copyright (c) 2018 by Thieme Revinter Publicações Ltda, Rio de Janeiro, Brazil
April 5, 2017

accepted

August 24, 2017

published online

October 25, 2017
DOI https://doi.org/

10.1055/s-0037-1606645. ISSN 1809-9777.
License terms

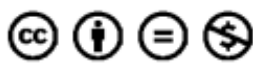


though arch bars are effective for rigid MMF, they are not devoid of negative aspects. Intermaxillary fixation (IMF) screws are similarly effective for rigid MMF regarding postoperative occlusion and MMF stability. Additionally, IMF screws have the advantages of decreasing the surgical time and gloves perforations, and of enabling better patient acceptance and oral hygiene. Accidental root perforation is the only limitation to IMF screws. ${ }^{10}$

The treatment of mandibular angle fractures represents a challenge due to their higher rate of complications, and there is currently no agreement as to the optimal treatment. The percutaneous approach using the transbuccal trocar technique provides easy access and fixation of the screws. Recently, ElAnwar and Sweed ${ }^{11}$ described a new, effective and simple percutaneous transbuccal approach using a modified cover of the cannula as a disposable available trocar for the admission and conduction of a microdrill shaft and screw driver directly to the fracture.

The familiarity with and popularity of these simpler effective trends in mandibular fracture repair will be very beneficial for surgeons, patients and the community in general.

\section{Financial Support}

The author received no financial support to write this letter.

\section{Conflicts of Interest}

The author has no conflicts of interest to disclose.

\section{References}

1 Kumar I, Singh V, Bhagol A, Goel M, Gandhi S. Supplemental maxillomandibular fixation with miniplate osteosynthesis-required or not? Oral Maxillofac Surg 2011;15(01):27-30

2 Spiessl B. Rigid internal fixation of fractures of the lower jaw. Reconstr Surg Traumatol 1972;13:124-140

3 Ellis E III, Miles BA. Fractures of the mandible: a technical perspective. Plast Reconstr Surg 2007;120(07, Suppl 2):76S-89S

4 El-Anwar MW, Sayed El-Ahl MA, Amer HS. Open reduction and internal fixation of mandibular fracture without rigid maxillomandibular fixation. Int Arch Otorhinolaryngol 2015;19(04):314-318

5 Gupta R, Surayana S, Pandya VK, et al. Traumatic mandibular fractures: Pendulum swinging towards closed reduction? World Articles of Ear, Nose, and Throat 2010;3:1

6 Haug RH, Assael LA. Outcomes of open versus closed treatment of mandibular subcondylar fractures. J Oral Maxillofac Surg 2001;59 (04):370-375, discussion 375-376

7 Singh B, Bhardwaj V. Continuous mandibular nerve block for pain relief. A report of two cases. Can J Anaesth 2002;49(09):951-953

8 Nacamuli RP, Longaker MT. Bone induction in craniofacial defects. Orthod Craniofac Res 2005;8(04):259-266

9 El-Anwar MW, Hegab A. Internal fixation of single mandibular fracture under mandibular nerve block. Oral Maxillofac Surg 2016;20(01):57-61

10 Qureshi AA, Reddy UK, Warad NM, Badal S, Jamadar AA, Qurishi N. Intermaxillary fixation screws versus Erich arch bars in mandibular fractures: A comparative study and review of literature. Ann Maxillofac Surg 2016;6(01):25-30

11 El-Anwar MW, Sweed AH. Simple percutaneous transbuccal approach for management of mandibular angular fracture. J Craniofac Surg 2017;28(04):1035-1037 